\title{
CARTOGRAFANDO AFETOS E APRENDIZADOS EM UMA ASSOCIAÇÃO CULTURAL AUTOGERIDA
}

\author{
Juliana de Meira ${ }^{1}$ (Psicologia - UEL) \\ Prof $^{\mathrm{a}}$ Alejandra Astrid León Cedeño (Orientadora)
}

\section{RESUMO}

Os moradores de bairros periféricos são submetidos a uma distância espacial e econômica de iniciativas culturais, visto que estas geralmente se localizam nas áreas centrais de cidades. Desse modo, os centros culturais comunitários tornam-se uma opção promissora. A partir da cartografia no cotidiano, buscou-se investigar os afetos que a Associação Ciranda da Cultura produz nas pessoas que a frequentam. Para tanto, a pesquisa foi dividida em dois momentos: 1) De outubro de 2014 a julho de 2015 foi realizada observação participante semanal da oficina de Histórias (na qual a pesquisadora é uma das oficineiras) e observação participante mensal das outras oficinas oferecidas diariamente no espaço, sendo ambas registradas em diário de campo; 2) Ao fim das observações e registros, foram feitas três rodas de conversa com os (as) participantes e oficineiros (as) do Ciranda sobre as experiências ali vividas. Pode-se considerar que as relações estabelecidas naquele espaço contribuem para a construção de características subjetivas capazes de provocar ações que ressoam no social e no comunitário.

Palavras-chave: Cartografia; Afeto; Cultura

\section{INTRODUÇÃO}

O afastamento das áreas centrais da cidade é comumente causa de diversos prejuízos; um deles é a dificuldade e, às vezes, impossibilidade de acesso ao lazer e à cultura, uma vez que os espaços culturais públicos ofertados pelo governo, como bibliotecas, teatros e museus, localizam-se na área central da cidade. (MARCELLINO, BARBOSA e MARIANO, 2006). Nesse sentido, de acordo com Freitas (2009), a periferia é entendida como um lugar afastado, especialmente de forma simbólica, dos espaços públicos de convivência de cultura e de lazer da cidade, em decorrência do processo histórico de exclusão social, racial, econômica, política e cultural. Essa exclusão torna-se ainda mais concreta quando se calcula o valor monetário do deslocamento da periferia até o centro. A questão do deslocamento, juntamente com seu alto custo, une a distância física a outro fator de afastamento do direito ao lazer: o âmbito econômico.

As relações estabelecidas no sistema capitalista, permeadas por propostas neoliberais de redução da esfera pública e do gasto social, asseguram a legitimidade dos bens privados, atribuindo valor monetário a objetos, serviços e mesmo a dimensão do tempo. A cultura e o lazer, nesse entorno, também sofreram um processo de mercantilização intensificado. Eventos, espetáculos, cursos, passeios e diversas outras

\footnotetext{
${ }^{1}$ Aluna de Iniciação Científica, julianademeiraa@gmail.com
} 


\section{SEMINÁRIO DE PESQUISA EM CIÊNCIAS HUMANAS - SEPECH \\ Humanidades, Estado e desafios didático-científicos \\ Londrina, 27 a 29 de julho de 2016}

formas de recreação possuem altos preços e não são acessíveis à grande parte da população. Embora haja avanços nas políticas culturais urbanas no Brasil, as cidades oferecem poucos espaços e escassas condições para que todos usufruam das manifestações culturais existentes, dessa forma, há a necessidade de encontrar novos ambientes e metodologias que favoreçam e possibilitem o lazer, a convivência e cultura. Tal ambiente pode ser reconhecido em centros culturais. (PINTO, PAULO e SILVA, 2012).

Quando se estudam os centros culturais é comum encontrar três nomeações: casas de cultura, centros culturais e espaços culturais. Segundo Teixeira-Coelho (1986, apud SILVA, 2013), nomeia-se "espaço cultural" quando o local é mantido pela iniciativa privada, como grandes empresas e instituições financeiras. $\mathrm{O}$ termo centro cultural está associado aos poderes públicos, de maior porte, com equipamentos permanentes, como teatros, cinemas, bibliotecas. E, por último, "casa de cultura" pode designar duas instituições com caráteres diferentes: pequena instituição com foco na divulgação de específica modalidade artística; pequeno centro cultural, localizado em região periférica da cidade. Essa última nomeação parece se aplicar à Associação Ciranda da Cultura.

A Associação Ciranda da Cultura, popularizada como "O Ciranda", foi fundada por moradores de um bairro da periferia de Londrina, estado do Paraná, em 1994. Inicialmente nomeado Movimento Cultural Ciranda, ensejava oficinas e eventos esporádicos pelo bairro, até 1998, quando dispôs de um espaço físico. Após esse fato, o Ciranda ofereceu oficinas fortuitas por cerca de dez anos, até chegar a uma dinâmica parecida com a atual. O Ciranda é localizado em um bairro que não apresenta muitas opções de lazer, e oferece oficinas recreativas, culturais e de saúde, além de ser um local aberto para articulações com políticas públicas, como a Unidade Básica de Saúde (UBS) e a Universidade Estadual de Londrina (UEL).

Entre o ano de 2014 e 2015 foram efetuadas oficinas de balé, alongamento, circo, kung fu, francês, vozes do Ciranda, cinema, arte para crianças (Cirandinha ${ }^{2}$ ), brincadeiras brasileiras, dança árabe, histórias, atividades do Levante e zumba, como oficinas constantes (de segunda-feira a sábado) e participações do Levante Popular da Juventude ${ }^{3}$, do Movimento de Artistas de Rua de Londrina ${ }^{4}$ (MARL) e do Sensibilizarte $\mathrm{UEL}^{5}$ como eventos e oficinas itinerantes. As atividades e oficinas propostas, com exceção das aulas de zumba ${ }^{6}$, não exigem pagamento; da mesma forma, as pessoas que ministram atividades e oficinas não são recompensadas financeiramente. Além disso, não há matrícula ou lista de presença; desse modo, os que ali estão presentes, seja ministrando oficinas ou participando, ali se encontram por manifestação de seu desejo.

\footnotetext{
${ }^{2}$ O nome desta oficina foi escolhido pelas crianças que dela participavam em 2011.

${ }^{3}$ Organização nacional de jovens voltada para a luta de massas em busca da transformação da sociedade. É dividida em três frentes: territorial, estudantil e camponesa. No Ciranda é a frente territorial que está presente. (http://levante.org.br/\#about)

${ }^{4}$ União de artistas que desenvolvem seus trabalhos em espaços público da cidade de Londrina.

${ }^{5}$ Projeto de extensão composto por estudantes da área da saúde da Universidade Estadual de Londrina, que atuam semanalmente no Hospital Universitário, através de quatro frentes: artesanato, contação de histórias, música e palhaço.

${ }^{6}$ Oficina oferecida por um morador de um bairro vizinho. Os participantes pagam mensalidade para o oficineiro. O Ciranda, nesse caso, é apenas o espaço de encontro e realização da oficina, não há retenção financeira para ele.
} 


\section{SEMINÁRIO DE PESQUISA EM CIÊNCIAS HUMANAS - SEPECH \\ Humanidades, Estado e desafios didático-científicos \\ Londrina, 27 a 29 de julho de 2016}

A Associação se mantém quase sem auxílio financeiro e é gerida através de uma lógica horizontal; a liderança do espaço é democrática e em muitos momentos coletiva. Dessa forma, o Ciranda pode ser entendido como um agrupamento contra hegemônico (LEÓN-CEDEÑO, 2006).

Gramsci (1999, apud MORAES, 2010) coloca as ações contra hegemônicas como instrumento para gerar uma nova forma ético-política, na qual se objetiva a denúncia e tentativa de modificação das condições de marginalização e exclusão impostas a amplos estratos sociais pelo modo de produção capitalista. Por possuir tal modo de funcionamento que não se utiliza da circulação direta de dinheiro, o Ciranda posiciona-se contrariamente à lógica do capital, que rege o modelo vigente.

Embora o que o Ciranda produz poderia ser estudado exclusivamente em sua forma organizativa, aprofundando a compreensão do seu funcionamento libertário enquanto agrupamento contra hegemônico, este estudo basear-se-á no conceito espinosano de afeto, de modo a entender o que embasa a potência inovadora do Ciranda. Destarte, um conceito transversal ao Ciranda é o de amizade política, que poderia resumir a multiplicidade de potências que a Associação Ciranda da Cultura desperta.

A partir da convivência existente na Associação, se constrói a possibilidade de estabelecimento de vínculo. Este, se regido pela abertura mútua ao outro, pode ser compreendido como amizade em sua forma política, desde que permita ao corpo a experiência de afetar e ser afetado por outros corpos, dos quais os efeitos podem fomentar transformações na subjetividade ou mesmo na potência de ação (SILVA; GOMES, 2013). Ainda segundo Silva e Gomes, a experimentação política da amizade sintetiza em si um dos principais postulados da filosofia espinosana: "o corpo humano pode ser afetado de muitas maneiras, pelas quais sua potência de agir é aumentada ou diminuída, enquanto outras não tornam sua potência de agir nem maior nem menor" (E.III. postulado 1. p. 163 apud SILVA; GOMES, 2013, p. 40).

Dessa forma, pretende-se pensar como os encontros proporcionados pela convivência no Ciranda podem vir a afetar os corpos das pessoas que o frequentam. Em outras palavras, o que a experiência do Ciranda é capaz de fazer surgir na vida de quem faz do centro cultural um lugar social para si e quais as ressonâncias disso no campo social desse indivíduo.

\section{TRAJETÓRIA METODOLÓGICA}

A realização deste trabalho partiu da perspectiva qualitativa e apoiou-se na proposta da cartografia. Desenvolvida por Gilles Deleuze e Félix Guattari, a cartografia se esforça para que a dicotomia sujeito-objeto seja rompida. Assim, não há separação entre objeto de estudo e pesquisador, não se parte da conjectura da neutralidade, já que a pesquisa é realizada em campo e o pesquisador é inserido no cotidiano deste, norteandose - ou sendo norteado - pela convivência e pelos afetos dela decorrentes.

Minha inserção no campo foi anterior ao período da pesquisa, a partir do projeto de pesquisa "Recantos de Beleza e Resistência: um estudo junto a centros culturais ecológicos como iniciativas de prevenção da violência", sugeri, em companhia de outras cinco alunas do terceiro ano de Psicologia da UEL, a abertura da oficina de contação de histórias, semanalmente, tendo o encontro duração de uma hora. 


\section{SEMINÁRIO DE PESQUISA EM CIÊNCIAS HUMANAS - SEPECH \\ Humanidades, Estado e desafios didático-científicos \\ Londrina, 27 a 29 de julho de 2016}

De acordo com Kastrup (2007), a cartografia se propõe a investigar processos de produção, portanto não há a busca por caminhos lineares visando atingir um determinado alvo. Nesse sentido, a condução da presente pesquisa pode ser dividida em dois momentos: corpo atento ao cotidiano e ouvido atento às experimentações.

Corpo atento ao cotidiano diz respeito ao período de observação participante e registro em diário de campo. De outubro de 2014 a julho de 2015, com exceção do período de férias da Universidade Estadual de Londrina, a oficina da qual sou uma das ministrantes foi registrada semanalmente em diário de campo. Durante o mesmo período algumas oficinas diárias oferecidas por outros participantes (Cirandinha, brincadeiras brasileiras, balé, dança árabe, francês, oficina do Levante e circo) foram visitadas e observadas participativamente na segunda semana de cada mês, sendo também registradas em diário de campo. Esse procedimento foi adotado para que fosse possível possuir um meio de auxílio de memória das experiências vistas, ouvidas e vividas.

Ouvido atento às experimentações se refere às rodas de conversa realizadas com os (as) frequentadores (as) do espaço. Assim, No final do período de observação e participação das oficinas, foram realizadas rodas de conversa com os participantes destas em três momentos diferentes: uma voltada para as experiências das crianças; outra para os (as) adolescentes e adultos (as) e a última para os (as) oficineiros (as). A roda com as crianças foi realizada após uma oficina de brincadeiras brasileiras, por ser a oficina que possui maior número de participantes. Deste modo, com a ajuda dos próprios oficineiros, sentamos todos em roda na parte externa do Ciranda. Inicialmente foi explicado sobre o trabalho e pediu-se que os participantes da roda pensassem em codinomes para si com um tema em comum. Foram escolhidos codinomes baseados em personagens de filmes e desenhos animados. As perguntas eram feitas pela pesquisadora e quem quisesse responder levantava a mão, dizia seu codinome e respondia. Os participantes tiveram liberdade para se manifestar quando sentissem vontade, assim como para deixar a roda, portanto não foi efetuada uma contagem de quantas pessoas estiveram presentes. A roda com os (as) adolescentes e as adultas foi realizada após uma oficina de dança do ventre, por esta ser uma das poucas oficinas que conta com a participação de pessoas com idade superior a 12 anos. Essa roda se desenvolveu no mesmo modelo que a roda com as crianças, com a diferença de que foi realizada no interior do Ciranda, na sala de usos múltiplos, e que não houve escolha de codinomes pelos participantes. A última roda de conversa, com as oficineiras e o oficineiro, foi realizada na Universidade Estadual de Londrina, durante uma reunião do projeto "Recantos de Beleza e Resistência". Dela participaram dois ministrantes da oficina de brincadeiras brasileiras, a oficineira de balé, duas ministrantes da oficina de histórias, uma oficineira de circo e atualmente de música e uma oficineira de dança do ventre.

As conversas foram realizadas para que se tivesse acesso às experiências de cada um a partir de um relato direto. Os participantes da roda voltada para adolescentes e adultas e da roda dirigida aos (as) oficineiros (as), receberam codinomes com as temáticas de pedras preciosas e de árvores, respectivamente. 


\section{SEMINÁRIO DE PESQUISA EM CIÊNCIAS HUMANAS - SEPECH \\ Humanidades, Estado e desafios didático-científicos \\ Londrina, 27 a 29 de julho de 2016}

\section{RESULTADOS E DISCUSSÃO}

O funcionamento livre e aberto da Associação auxilia na construção de atributos importantes para o próprio desenvolvimento do indivíduo, sendo também essenciais para a ação deste na comunidade, estes são o autoconhecimento e o empoderamento. $\mathrm{O}$ autoconhecimento se revela no saber se relacionar com o mundo ao redor. Portanto, o autoconhecimento é constituído no meio social. Ao relacionar-se e conhecer o mundo, esse mundo permite que o sujeito se conheça.

Uma situação possível de ser lida como autoconhecimento é explicitada pela fala de Margarida ${ }^{7}$, uma mulher que frequenta a oficina de dança do ventre há dois anos e meio. Margarida conta o que percebeu ter mudado em si mesma após ter começado a dançar: Pra mim mudou bastante expressão corporal. Estou aprendendo a trabalhar com o corpo e postura. Sempre cabeça erguida, como uma princesa. (Margarida)

Ao trabalhar com o corpo e aprender sobre sua postura, Margarida possui mais consciência de si. Essa mudança que parece tão individual e subjetiva pode ser suficiente para modificar os modos de se relacionar com seu próprio mundo, como expressa Santos (2014) ao dizer que ao trabalhar a consciência do movimento, há a produção de um processo de autoconhecimento, de libertação e de criatividade que é capaz de permitir ao indivíduo situar-se melhor na sociedade e na (re) construção de sua própria identidade.

Além dessa situação, o próprio modo de se relacionar proporcionado pela liberdade de experimentação possível na associação permite que os frequentadores sintam em seus corpos quais afecções os compõem e quais os decompõem. A oficineira de balé conta como a possibilidade de dar aula no Ciranda a modificou: (...) eu fui dar aula achando "ah, vou tentar, não sei se sou boa nisso" e eu percebi que é minha paixão, sabe? E eu quero fazer isso pra vida. (Manacá)

Em outro momento, uma garota de dez anos, chamada aqui de Zuko, não possui afinidade pela dança, mas cultiva afeição pela oficineira de dança. Então Zuko combina com a oficineira que irá para as aulas, mas não participará. Em outra situação, a garota percebeu - e diz, com essas palavras - que determinada oficina não lhe interessa e deixa de frequentá-la. Nesse caso, Zuko participou de ambas oficinas, seu corpo sentiu as afecções das atividades, mas apenas a oficineira de dança a afetou. Na linha espinosana, esse encontro compõe com o corpo de Zuko; saber disso e organizar-se de modo a estar em encontros que compõem consiste na Ética da vida (DELEUZE, 2002). "Por meio desse poder de ordenar e concatenar corretamente as afecções do corpo podemos fazer com que não sejamos facilmente afetados por maus afetos" (SPINOZA, Ética V, prop. 10, esc.). Os maus encontros, de acordo com Deleuze (2002), diminuem a potência de agir; antagonicamente, os bons encontros aumentam a potência de agir. Se o indivíduo conhece os encontros que o compõem e decompõem, ele pode organizá-los de maneira a aumentar sua potência de ação. Então se chega ao segundo atributo, o empoderamento.

O empoderamento é um termo que designa a obtenção, aplicação ou reforço do poder. Este pode ser individual, organizacional ou comunitário (BAQUERO, 2012). De acordo com Baquero, empoderamento no nível individual diz respeito à habilidade do indivíduo de conhecer e controlar suas forças pessoais de modo a ir em direção a melhorias na própria vida. Esse processo, além de intrapessoal, é relacional,

\footnotetext{
${ }^{7}$ Todos os nomes foram substituídos por codinomes.
} 


\section{SEMINÁRIO DE PESQUISA EM CIÊNCIAS HUMANAS - SEPECH \\ Humanidades, Estado e desafios didático-científicos \\ Londrina, 27 a 29 de julho de 2016}

influenciado pelas interações do sujeito com o ambiente (BAQUERO, 2012, APUD ZIMMERMAN, s/d, apud HOROCHOVSKI e MEIRELLES, 2007); o empoderamento no nível organizacional aborda o processo de trabalho de maneira a objetivar a autonomia e participação dos funcionários na administração, horizontalizando e coletivizando as decisões; já o empoderamento comunitário se refere a processos de sujeitos de uma comunidade, organizados em coletivos ou individualmente, que desenvolvem ações para conquistar objetivos coletivamente definidos. (BAQUERO, 2012).

$\mathrm{O}$ processo de empoderamento individual se aproxima muito do autoconhecimento organizador de bons encontros. Em ambos as vivências no público proporcionam o conhecimento do privado, favorecendo a organização do que compõe o corpo e aumenta sua potência de agir. Ademais o empoderamento organizacional é similar ao modo contra hegemônico de funcionamento do Ciranda, com exceção de que na Associação o lucro (intelectual e afetivo) é de todos. Por último, o empoderamento comunitário cabe perfeitamente em uma situação vivida há cerca de um ano por quem frequenta o Ciranda e habita o bairro. Durante uma oficina de formação política, foi pedido que levantassem os problemas do bairro. Os moradores expuseram o cenário do momento: um trecho de uma rua estreita e perigosa estava todo esburacado e sem iluminação, potencializando o perigo para os motoristas e os pedestres. A partir disso, foram confeccionados cartazes e decidida uma data para um protesto de reivindicação. Os moradores foram ouvidos e tiveram essas demandas atendidas.

Assim, a Associação Ciranda da Cultura auxiliando na promoção desses dois atributos, autoconhecimento e empoderamento, auxilia também na promoção de condições mais igualitárias na busca por melhorias pessoais e coletivas.

Um outro afeto emerge neste processo: a construção da lógica da convivência, ou mais precisamente, a amizade política no cotidiano. O local, constituído e desenvolvido a partir de relações de amizade, também oportuniza que as mesmas sejam construídas no dia-a-dia das oficinas e para além delas, como expresso por diversas crianças durante a roda de conversa:

Antes do Ciranda eu ficava sozinha em casa e não brincava com ninguém. Aí depois que eu vim no Ciranda, eu comecei a brincar com todas as pessoas do Ciranda. (Olaf)

Eu antes eu não conhecia o Ciranda e eu não tinha ninguém pra brincar, ficava só no videogame. (Bart)

Antes, à tarde, eu não tinha nada pra fazer; eu ficava em casa emburrada no computador e agora toda tarde eu venho me divertir no Ciranda. (Zuko)

Antes de vir no Ciranda eu não fazia nada, só ficava de castigo. (Avatar Aang)

Desse modo, a Associação pode ser configurada como um lugar em que são frequentes as trocas e os encontros. Como diz Tadeu (2002), o corpo se define a partir de um encontro; até este momento o corpo não nos comunica muito, mas através dos encontros sabemos o que pode um corpo. Acredito que o Ciranda propicie mais encontros que compõem com o corpo dos frequentadores, do que encontros que o 


\section{SEMINÁRIO DE PESQUISA EM CIÊNCIAS HUMANAS - SEPECH \\ Humanidades, Estado e desafios didático-científicos \\ Londrina, 27 a 29 de julho de 2016}

decompõem, uma vez que as pessoas são livres para chegar e para partir. As oficineiras se manifestam quanto a esse espaço livre e potente:

Eu acho que o Ciranda é uma escola que ensina a fazer tudo de forma mais livre e de forma mais unida. Eu venho de uma companhia de dança que funciona muito mais rígido do que aqui e aqui eu aprendo a fazer as coisas adaptando às necessidades das pessoas e não as pessoas terem que se adaptar à dança que tem: o contrário. $\mathrm{O}$ que eu aprendo aqui eu uso pra tudo o que faço na minha vida e no meu trabalho (...) Então, acho que o Ciranda é um lugar muito potente, que ensina muito pra gente e eu acredito que vai continuar ensinando pra sempre. (Safira, oficineira de dança árabe)

Tem duas coisas que eu pensei. Uma delas é quando eu desço do ônibus, normalmente depois de um dia bem cansativo; aí eu desço do ônibus e já aparecem algumas criancinhas no muro e vão correndo me abraçar. Essa é uma das coisas que eu gosto. E a outra é, talvez, [...] a não autoridade assim, sabe? Elas vão me abraçar e eu sei que aquilo não é a minha aula e também ao mesmo tempo não é delas e eu só vou estar lá observando. Eu chego e falo 'ó, e aí, tudo bem? Vamos fazer alguma coisa? Eu pensei nisto'. E se elas não quiserem fazer, a gente vai construir outra coisa sabe? Mas é como a gente consegue estabelecer essa relação, assim, de criar. (Acácia, oficineira de circo, expressão corporal e música).

(...) o quanto que isso dá potência a todo mundo que participa, sabe. Porque não tem que ter um formato, você não tem que ser um aluno ideal, porque a escola não potencializa todo mundo; o Ciranda tem essa capacidade, de potencializar todo mundo dentro do que tá nele já, sabe. Por exemplo, eu dou aula de dança, mas tem gente que vai se potencializar na dança, tem gente que vai se potencializar no corpo, tem gente que vai se potencializar no vínculo com os amigos, tem gente que vai se potencializar na colaboração, então tipo é muito isso, cabe todo mundo, cabe a potência de todo mundo. (Manacá, oficineira de balé).

Essas vivências expressas tocam na questão das afeições e afetos, estes no sentido espinosano, ali construídos. É explícito, tanto nas observações registradas em diário de campo como nos relatos das crianças, adolescentes, adultas e oficineiros (as), a relação de carinho e proximidade formada, seja dos participantes com os oficineiros, dos oficineiros com os participantes ou de todos com o Ciranda.

Bom, o que mais me chamou atenção, que eu acho que me segurou assim no Ciranda, principalmente, né, foi a questão de afetos, de relacionamento que a gente criou assim com as crianças. É muito de chegar e abraçar. (Ipê, oficineira de histórias).

Eu gosto do Ciranda por causa das professora que são muito legal. (Goku, participante das oficinas).

Silva e Gomes (2013) explicitam que a experimentação política da amizade indica a implicação com a composição de espaços democráticos de trocas de saberes e 


\section{SEMINÁRIO DE PESQUISA EM CIÊNCIAS HUMANAS - SEPECH \\ Humanidades, Estado e desafios didático-científicos \\ Londrina, 27 a 29 de julho de 2016}

experiências, nas quais podemos afetar e sermos afetados em nossas relações cotidianas, de maneira a contribuir no processo coletivo de construção da cidadania. Nesse sentido, as falas de Pérola e Esmeralda vão de encontro à concepção de amizade política:

(...) São momentos que a gente vive e, assim, a convivência com as pessoas que dá essa energia, essa alegria; são momentos que a gente esquece das coisas lá fora, até. (Pérola)

A gente tá aqui num espaço de compartilhar um monte de coisas, assim né? Então a gente acaba, a gente acaba ficando mais leve, a gente acaba vendo que a gente tem companheiras junto com a gente pra fazer as coisas, sabe? Fica mais forte né. O Ciranda é um lugar meio único assim, né? (Esmeralda, oficineira de dança árabe)

Esse espaço de troca de afetos, atenção, conversa e de convivência, permeado por relações horizontais, possibilita que as pessoas se sintam abertas a manifestarem-se livremente, favorecendo a experimentação e colocando seus frequentadores no lugar de sujeito da experiência, permitindo que novos territórios sejam construídos e percorridos.

\section{CONSIDERAÇÕES FINAIS}

O modo de organização da Associação Ciranda da Cultura, partindo da contra hegemonia, atua enquanto causa e efeito das relações horizontais ali vivenciadas, promovendo transformações no cotidiano do Ciranda, do bairro em que ele está inserido e das pessoas que por ele são afetadas. Cada pessoa leva consigo essa maneira mais libertária de se posicionar frente ao seu mundo para os diversos lugares em que vão e que ainda possuem uma estrutura rígida disciplinar, capaz de decompor corpos, como escola, universidade, família, emprego e políticas públicas.

Em organizações como essas o mais comum é que exista uma hierarquia e, decorrente desta, o tratamento "de cima para baixo". Espaços com dinâmicas como essas tolhem o sentimento de pertencimento, contribuindo para que ocorra a dispersão das pessoas e a decorrente impossibilidade de uma vivência participativa. O Ciranda, nesse sentido, posiciona-se como uma alternativa aos modelos vigentes, se apresentando como um espaço potente de formação do psicólogo para o trabalho em serviços de convivência e fortalecimento de vínculos, bem como na promoção da saúde dos seus participantes, organizadores e oficineiros. Destarte, nos afetos e territórios que produz, o Ciranda rompe com a dicotomia sujeito-objeto, ou interventor-beneficiário, através de práticas cotidianas de amizade política, que afetam os corpos de forma intensa, muitas vezes aumentando sua potência de agir.

Além disso, o Ciranda parece ser capaz de reduzir o distanciamento do seu bairro a respeito de iniciativas culturais e de lazer. Contudo, cabe criticar a falta de iniciativas culturais públicas e trabalhar para que o autoconhecimento e empoderamento, construídos a partir das relações presentes em espaços como esse, possam criar corpos de luta, que continuem exigindo que os direitos sociais garantidos na Constituição Federal, como o direito ao lazer e à cultura, entre outros indispensáveis, sejam assegurados. 


\section{SEMINÁRIO DE PESQUISA EM CIÊNCIAS HUMANAS - SEPECH \\ Humanidades, Estado e desafios didático-científicos \\ Londrina, 27 a 29 de julho de 2016}

\section{REFERÊNCIAS BIBLIOGRÁFICAS}

BAQUERO, R. V. A.; Empoderamento: Instrumento de emancipação social? - Uma discussão conceitual. Revista Debates, Porto Alegre, v.6, n.1, p. 173-187, jan.-abr. 2012.

DELEUZE, Gilles. Espinosa: Filosofia prática. Tradução de Daniel Lins e Fabien Pascal Lins. São Paulo: Escuta Editora, 2002.

KASTRUP, Virgínia. O funcionamento da atenção no trabalho do cartógrafo. Psicol. Soc., Porto Alegre , v. 19, n. 1, p. 15-22, abr. 2007 . Disponível em $<$ http://www.scielo.br/scielo.php?script=sci_arttext\&pid=S0102-

71822007000100003\&lng=pt\&nrm=iso $>$. Acesso em 03 mar. 2015. http://dx.doi.org/10.1590/S0102-71822007000100003.

LEÓN-CEDEÑO, A. A. Emancipação no cotidiano: iniciativas igualitárias em sociedades de controle. 2006. 331 f. Tese (Doutorado em Psicologia Social), Pontifícia Universidade Católica de São Paulo, São Paulo, 2006.

MARCELLINO, N. C.; BARBOSA, F. S.; MARIANO, S. H. As cidades e o acesso aos espaços e equipamentos de lazer. Impulso, Piracicaba, 17(44): 55-66, 2006. Disponível em: http://www.unimep.br/phpg/editora/revistaspdf/imp44art04.pdf. Acesso em: 20/08/2015

MORAES, D. Comunicação, hegemonia e contra-hegemonia: a contribuição teórica de Gramsci. Revista Debates, Porto Alegre, v.4, n.1, p. 54-77, jan.-jun. 2010.

PINTO, G. B.; PAULO, E.; SILVA, T. C. Os centros culturais como espaço de lazer comunitário: o caso de Belo Horizonte. 2012. Disponível em: http://www.uesc.br/revistas/culturaeturismo/ano6-edicao2/6.espaco-cultural.pdf Acesso em: 10/08/2015

SANTOS, K. S. M. Corpo: Instrumentos de autoconhecimento na dança e dança. Escola de educação Básica, Universidade Federal de Uberlândia. Revista Olhares e $\begin{array}{lllll}\text { Trilhas, } & \text { ano XVI, Número } & \text { 19, Jan./Jun. }\end{array}$ (http://www.seer.ufu.br/index.php/olharesetrilhas)(

http://www.seer.ufu.br/index.php/olharesetrilhas/article/viewFile/14660/12995)

SILVA, M. F. Centros Culturais: Análise da produção bibliográfica. 2013. 206 f. Dissertação (Mestrado em Hospitalidade) - Universidade Anhembi Morumbi. São Paulo, 2013. Disponível em: http://portal.anhembi.br/wpcontent/uploads/dissertacoes_mestrado/dissertacao_mario-fernandes-da-silva.pdf.

Acesso em: 11/08/2015

SILVA, N. J. GOMES, L. G. N. Experimentação política da amizade a partir da teoria dos afetos de Espinosa; Cadernos Espinosanos / Estudos Sobre o século XVII, São 


\section{SEMINÁRIO DE PESQUISA EM CIÊNCIAS HUMANAS - SEPECH \\ Humanidades, Estado e desafios didático-científicos}

Londrina, 27 a 29 de julho de 2016

Paulo: Departamento de Filosofia da FFLCH-USP, 1996-2013.Periodicidade semestral. P. 41

SPINOZA, Benedictus de. Ética. Tradução de Tomaz Tadeu. Belo Horizonte: Autêntica Editora, 2009. 